\title{
ESTUDO DA RESISTÊNCIA SUPERFICIAL DE ESTACAS DE FUNDAÇÃO EM CONCRETO ARMADO POR ESCLEROMETRIA DE REFLEXÃO E POR EXTRAÇÃO DE TESTEMUNHOS
}

\section{ARTIGO ORIGINAL}

LÁZARO, Bruno de Oliveira ${ }^{1}$

CUNHA, Rodrigo Rodrigues da ${ }^{2}$

OLIVEIRA, Andrielli Morais de ${ }^{3}$

LÁZARO, Bruno de Oliveira. CUNHA, Rodrigo Rodrigues da. OLIVEIRA, Andrielli Morais de. Estudo da resistência superficial de estacas de fundação em concreto armado por esclerometria de Reflexão e por extração de testemunhos. Revista Científica Multidisciplinar Núcleo do Conhecimento. Ano 04, Ed. 07, Vol. 10, pp. 2031. Julho de 2019. ISSN: 2448-0959

\section{RESUMO}

Elementos de fundação são componentes fundamentais de um sistema estrutural, responsáveis por distribuir as cargas provenientes de uma edificação no solo e demandam por uma eficiente concepção, projeto, execução e monitoramento. Tradicionalmente, podem ser empregadas inúmeras metodologias para o estudo e análise destes elementos, sendo os testes de averiguação de dureza superficial por esclerômetros de reflexão e a extração de testemunhos tem possibilidades de utilização. Estes ensaios podem oferecer resultados coerentes para análises estruturais. Neste sentido, o presente trabalho realiza um estudo de avaliação da resistência à compressão em sete elementos de fundação do tipo hélice contínua em

\footnotetext{
${ }^{1}$ Graduando em engenharia civil.

${ }^{2}$ Mestre e doutorando em engenharia civil.

${ }^{3}$ Doutora em engenharia civil.
} 
concreto armado de um viaduto do sistema BRT (Bus Rapid Transit) na cidade de Belém - PA, por meio dos ensaios de esclerometria de reflexão e da extração de testemunhos. Com estes ensaios, foi possível observar que a resistência superficial e a avaliada por extração de testemunhos das estacas de fundação foi inferior a de projeto. Assim, dada a não conformidade da resistência medida com a especificada em projeto, este trabalho levantou hipóteses para o comportamento observado e sugeriu ações de reparo e adequação da estrutura de fundação à resistência de projeto, de modo a garantir a integridade estrutural da infraestrutura analisada.

Palavras-chave: Esclerometria, fundações, resistência.

\section{INTRODUÇÃO}

Nos últimos anos, é crescente a preocupação com durabilidade e desempenho de elementos estruturais e seu comportamento com o tempo. Neste contexto, fundações merecem especial destaque por que são responsáveis por absorver e redistribuir cargas provenientes da estrutura, assim como pela estabilidade da edificação.

Adicionalmente, o comportamento de um elemento de fundação no período pós obra pode diferir-se daquele esperado teoricamente durante a fase de concepção e projeto da mesma. Pode ocorrer que a resistência real aos esforços compressivos em um elemento de fundação seja inferior à resistência teórica limite de projeto.

Diante deste cenário, é interessante avaliar os valores de resistência real (medida) e a resistência teórica (em projeto) para a fundação. Esta avaliação serve como instrumento para assegurar que o gradiente de variação esteja dentro de limites aceitáveis, estipulados em normas por meio de coeficientes de segurança, garantindo assim a estabilidade da estrutura no geral.

Neste sentido, o presente trabalho objetiva realizar um estudo de avaliação da resistência superficial de sete elementos de fundação do tipo estaca de hélice contínua em concreto armado. Estes elementos fazem parte da fundação geral de um 
viaduto integrante do sistema BRT (Bus Rapid Transit) da cidade de Belém - PA, Brasil.

Para a promoção deste estudo, aplicou-se a metodologia dos ensaios de Esclerometria de Reflexão, normatizados pela ABNT NBR 7584: 2013 e Extração, Preparo, Ensaio e Análise de Testemunhos de Estruturas de Concreto, e Resistência à Compressão Axial (ABNT NBR 7680, 2015). Os testes previstos nestas normas foram realizados em sete estacas e foram, assim, determinados os valores de resistência superficial (ou dureza superficial) e real (por meio de testemunhos) das mesmas.

\section{FUNDAMENTAÇÃO TEÓRICA}

As fundações do tipo estacam hélice contínua ("continuous flight auger") foram introduzidas no Brasil em 1987 e difundidas mais amplamente a partir do ano de 1993. Estes elementos são muito utilizados em obras de fundações dos mais diversos tipos de edifícios devido ao controle que se tem de seu processo construtivo e à possibilidade de execução em diversos tipos de subsolo (CAPUTO et al., 1997).

Este tipo de estaca é moldado in loco, sendo caracterizada pela escavação do solo por meio de um trado contínuo que possui hélices em torno de um tubo central vazado. A fim de se evitar a entrada de água ou solo no fuste da estaca, promove-se a introdução de uma tampa metálica na face inferior do tubo vazado. Esta tampa, gradativamente, é expulsa do diâmetro do fuste por meio da pressão do concreto bombeado para dentro da área da estaca (PENNA et al., 1999).

Após a sua introdução no solo, até a cota especificada, o trado é extraído concomitantemente à injeção do concreto através do tubo vazado (Figura 1). Deste modo, à medida que o trado é retirado, o solo confinado entre as pás da hélice é removido. Para este tipo de estaca de fundação, utiliza-se geralmente concreto com uma mistura de agregados miúdos (pedrisco e areia), com consumo mínimo de cimento da ordem de $400 \mathrm{~kg} / \mathrm{m}^{3}$ e abatimento da ordem da $240 \mathrm{~mm}$ (ANTUNES; TAROZZO, 1996). 
Atualmente, diversas empresas no território nacional executam este tipo de fundação, de modo a destacar como seus principais benefícios e vantagens a redução de tempo no cronograma de obras, a possibilidade de utilização em vários tipos de solo, a ausência de distúrbios e vibrações e a mínima geração de resíduos.

Todavia, as fundações do tipo estacam hélice contínua apresentam algumas desvantagens que devem ser consideradas. Entre estas, pode-se destacar o elevado custo de aquisição dos equipamentos de execução, a necessidade de uma central fornecedora de concreto próximo ao local da fundação e a exigência por uma quantidade suficiente de estacas para justificar o custo de execução.

Neste sentido, um dos principais problemas construtivos que as fundações do tipo estacam hélice contínua podem apresentar é uma resistência mecânica à compressão menor do que a resistência especificada em projeto ${ }^{[4]}$. Quando isso ocorre, a capacidade de carga da estaca pode ser reduzida drasticamente, o que pode colocar em risco à integridade estrutural global do edifício sustentado pela fundação.

Não é comum a realização de ensaios de averiguação de resistência "In loco" em elementos de estruturais de fundações justamente pelas condições de confinamento da peça. A ABNT NBR 6118: 2014 específica resistências à compressão mínimas de $20 \mathrm{MPa}$ aos 28 dias mesmo para fundações.

Uma das técnicas mais amplamente utilizadas para a avaliação da resistência à compressão indireta ou dureza superficial de estruturas consiste na utilização de esclerômetros de reflexão (Figura 1). Estes aparelhos são constituídos por uma massa/martelo que, quando impulsionada por uma mola elástica, defere um golpe contra a superfície do elemento que se deseja aferir a dureza superficial, liberando uma dada quantidade de energia mecânica. 
Figura 1 - Esquema de funcionamento de um esclerômetro de reflexão.
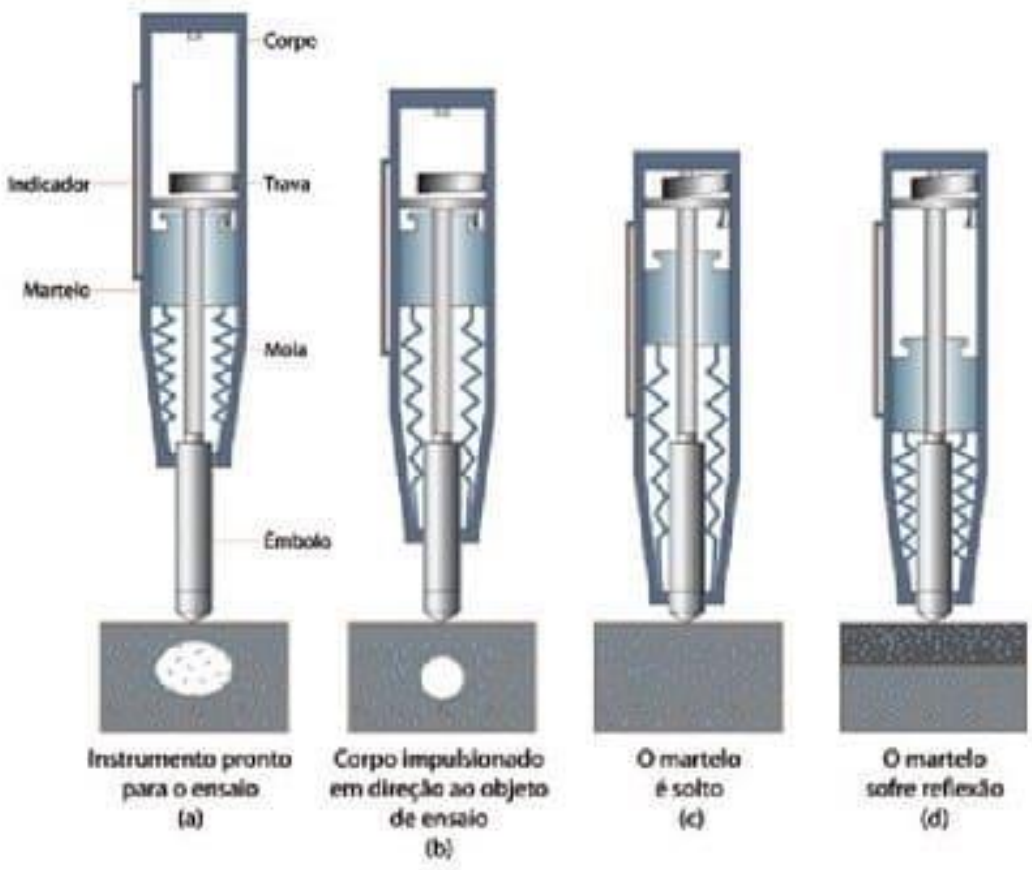

Fonte: (MEHTA; MONTEIRO, 2014).

Esta energia é parcialmente utilizada para se promover a deformação permanente na área superficial impactada. Já a outra parte desta energia é conservada de modo elástico, o que proporciona o retorno da massa/martelo a uma posição próxima da inicial. Assim, de forma simplificada, a variação entre a posição inicial da massa/martelo e sua posição final indica o valor de dureza superficial do elemento que sofreu o impacto (MEHTA; MONTEIRO, 2014).

Nesse sentido, observa-se que quanto maior for a dureza da superfície impactada (elemento a ser estudado), menor será a parcela de energia mecânica que se converte em deformação permanente. Assim, maior será a parcela que é conservada de modo elástico e promove o retorno da massa/martelo a uma posição próxima da inicial. Desde modo, a dureza (ou resistência) superficial do elemento ensaiado é diretamente proporcional à reflexão da massa/martelo (NEVILLE, 1997).

Assim sendo, o ensaio de esclerometria de reflexão se configura como uma técnica de avaliação da resistência superficial de elementos estruturais não destrutiva, visto 
que não causa danos à seção transversal e à superfície da peça analisada. Além disso, esse método não gera nenhum tipo de perda na capacidade de resistência do elemento que será ensaiado, de modo a não influenciar no resultado final do experimento (NEVILLE, 1997).

Portanto, salienta-se que a esclerometria de reflexão é uma metodologia de avaliação da dureza superficial de diversos tipos de elementos estruturais com grandes vantagens, entre as quais se podem destacar:

- Baixo custo de aquisição do equipamento (esclerômetros mecânicos ou digitais);

- fácil manuseio e interpretação dos resultados do esclerômetro;

- rapidez de aplicação e obtenção dos resultados e

- baixa possibilidade de ocorrência de danos estruturais na peça analisada.

\subsection{METODOLOGIA EXPERIMENTAL: MATERIAIS E MÉTODOS}

Para se avaliar a dureza superficial dos elementos de fundação da construção de um viaduto em Belém - PA, integrante do sistema BRT da cidade, este trabalho seguiu os procedimentos metodológicos explicitados na ABNT NBR 7584/2013 - Avaliação da dureza superficial por esclerômetro de reflexão. Assim, foram eleitas sete estacas para a realização do ensaio, conforme descrito a seguir.

Primeiramente, foi escavado e exumado 7 metros dos 20 metros totais de profundidade das sete estacas. Nesta etapa, a superfície lateral das estacas foi lavada, seca e regularizada de modo a evitar resíduos e/ou asperezas na área a ser ensaiada. Além disso, a superfície das estacas foi lixada, tentando manter uma uniformidade superficial.

Após este processo, desenhou-se em cada estaca uma quadrícula com 16 elementos de área, conforme especificado em norma (Figuras 2). Cada elemento de área receberia, após os procedimentos de preparo da superfície, um golpe com o 
esclerômetro de reflexão com a finalidade de se medir a resistência superficial da peça em questão.

Figuras 2 - Delimitação da área de ensaio das estacas (a) estaca de número 100 e (b) estaca de número 106.

(a)

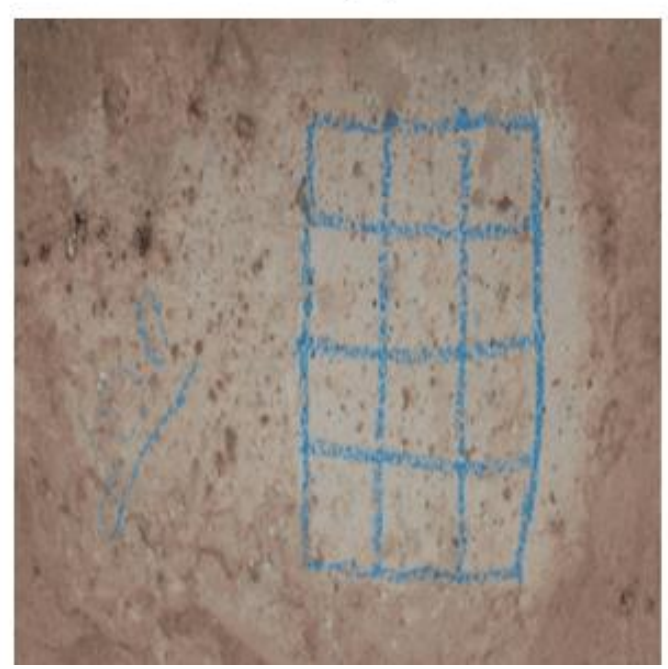

(b)

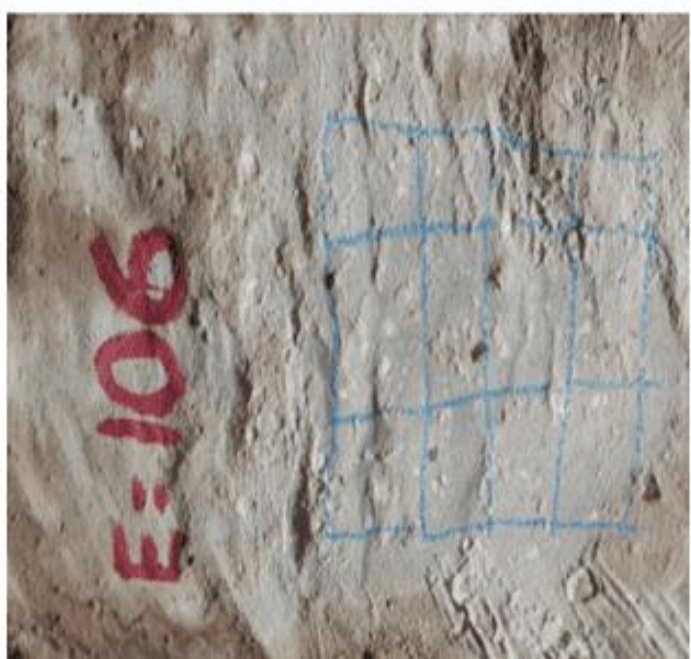

Fonte: Autores (2018).

Após a delimitação da área de ensaio, aplicou-se o esclerômetro de reflexão em cada uma das 16 quadrículas nas sete estacas isoladas para o procedimento experimental (Figura 2). Deste modo, em cada estaca, foram efetuados 16 impactos sucessivos, uniformemente distribuídos na área superficial de ensaio desenhada na estaca (Figura 3). Buscou-se evitar a promoção de impactos diretamente sobre agregados, bolhas e outras anomalias na estrutura do concreto dos elementos da fundação. Esse critério foi apenas visual. 
Figura 3 - Aplicação dos impactos pelo esclerômetro de reflexão.

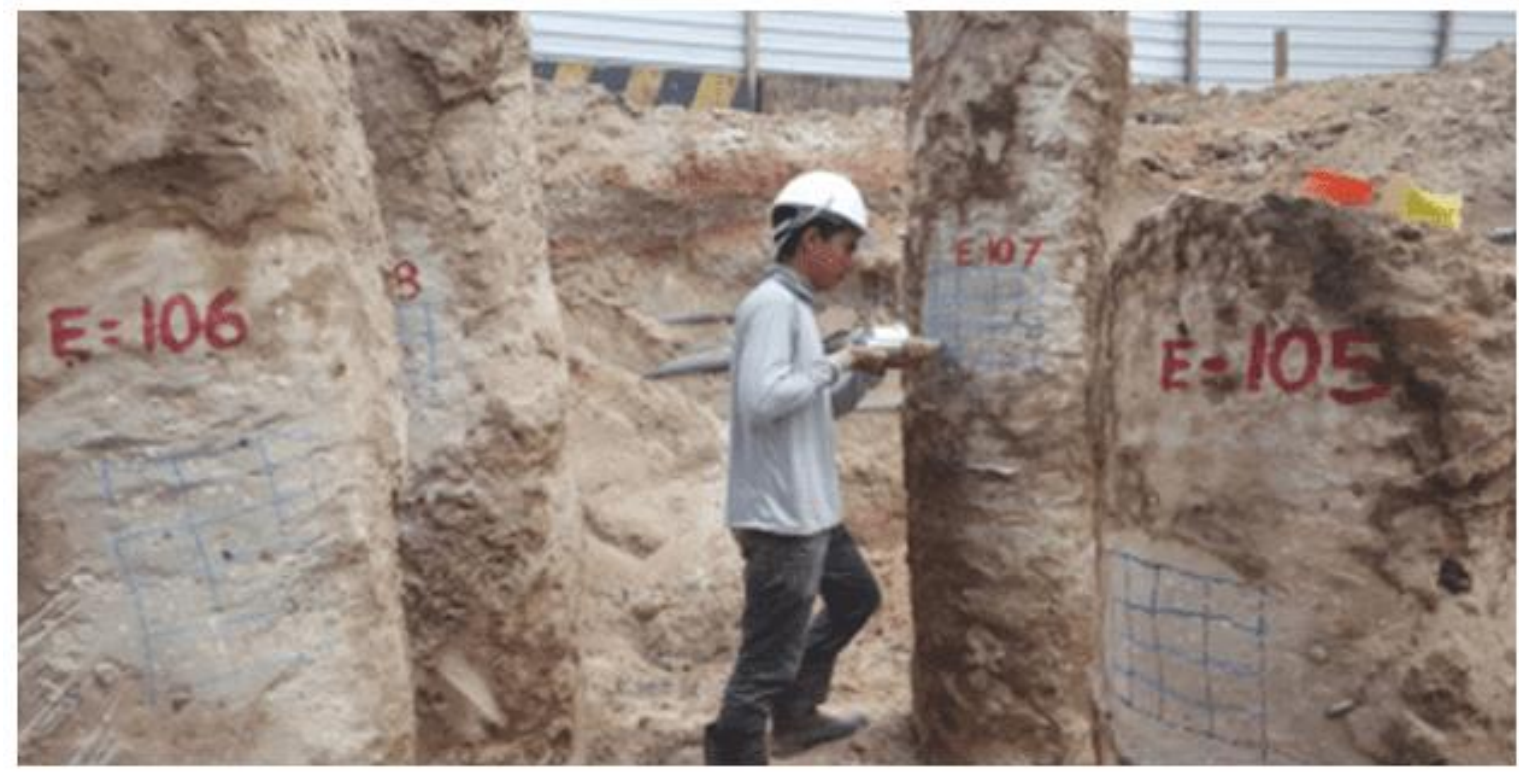

Fonte: Autores (2018).

Cada golpe do esclerômetro foi aplicado de modo que o martelo do equipamento estivesse perpendicular ao eixo de maior inércia do elemento de fundação. Após cada impacto, aferiu-se o índice esclerométrico da área na quadrícula impactada. Terminados os 16 impactos, calculou-se a média dos valores de índices esclerométricos lidos no aparelho para cada uma das quadrículas desenhadas, calculando-se o Índice Esclerométrico de cada estaca.

Após o cálculo do Índice Esclerométrico total (IE) de cada estaca, eliminou-se os valores de índices esclerométricos individuais inferiores e superiores a 10\% do IE total. Com isso, recalculou-se o valor do IE total e adotou-se este novo resultado como o valor de dureza superficial real do elemento estrutural de fundação analisado.

Após este procedimento, foram realizados também ensaios de extração de testemunhos para determinação da resistência à compressão. Este ensaio permitiu realizar uma nova análise sobre a dureza superficial das estacas do tipo hélice contínua e serviram como contra-prova para os resultados dos ensaios de esclerometria, complementando-os. 
As extrações dos testemunhos foram realizadas na direção ortogonal ao lançamento do concreto, toda extração teve de ser precedida de um escoramento adequado, sempre que necessário. A superfície da estrutura, na região de extração do testemunho foi preparada e o testemunho extraído com disco rotativo, refrigerado a água, sem uso de percussão (martelete). $O$ diâmetro do exemplar foi de $7,4 \mathrm{~cm}$, garantindo que seja maior três vezes a dimensão máxima característica do agregado graúdo, como prevê a ABNT NBR 7680: 2015.

A relação altura/diâmetro do testemunho capeado foi igual a dois. Evitando extrair pedaços de armadura, a extração foi precedida de uma verificação experimental do seu posicionamento, concomitantemente com o estudo do projeto estrutural. Após retirados da estrutura, os testemunhos foram envolvidos em sacos plásticos e acondicionados em caixa de areia e serragem, para evitar impactos e ações danosas que comprometeriam a integridade das amostras. A Figura 4 apresenta os locais de corte na estaca e os corpos de prova após a extração da estaca.

Figuras 4 - Preparação de corpos de prova para o teste de resistência à compressão: (a) corte e (b) extração de testemunhos.

(a)

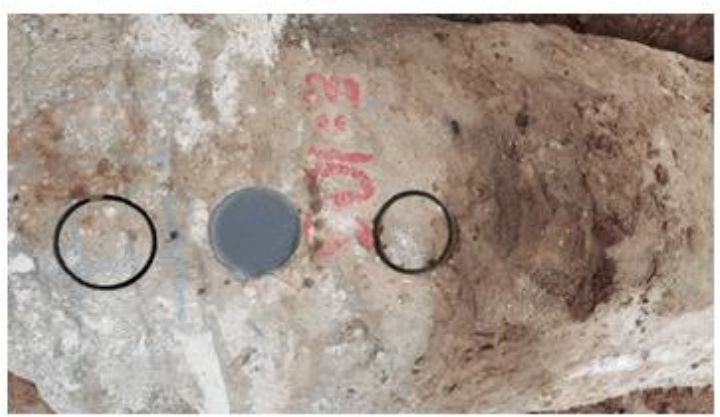

(b)

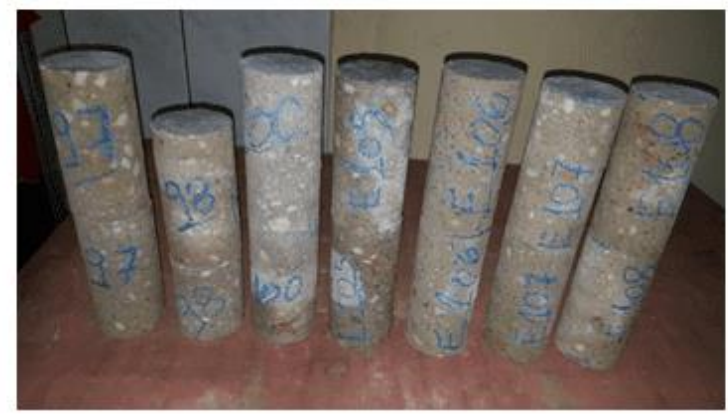

Fonte: Autores (2018). 


\section{APRESENTAÇÃO E DISCUSSÃO DOS RESULTADOS}

\subsection{ANÁLISE DA ESCLEROMETRIA DE REFLEXÃO}

A Tabela 1 apresenta os resultados obtidos por meio da aplicação de esclerometria de reflexão sob a superfície das 7 estacas avaliadas.

Tabela 1 - Resultados do ensaio de esclerometria.

\begin{tabular}{|l|l|l|l|l|l|l|l|}
\hline PROPRIEDADE & EST & EST & EST & EST & EST & EST & EST \\
& 97 & 98 & 100 & 105 & 106 & 107 & 108 \\
\hline Média (MPa) & 22,9 & 22,2 & 23,5 & 23,6 & 28,2 & 26,8 & 23,7 \\
\hline $\begin{array}{l}\text { Desvio Padrão (MPa) } \\
\text { Coeficiente De }\end{array}$ & 3,4 & 11,6 & 1,6 & 3,1 & 4,8 & 2,4 & 4,2 \\
Variação (\%) & & & & & & & \\
\hline
\end{tabular}

Fonte: Autores (2018).

Os valores representados na Tabela 1 são referentes ao valor da determinação do índice esclerométrico médio para cada estaca analisada. Neste sentido, observa-se que este parâmetro variou entre 22,2 MPa 28,2 MPa nas sete estacas ensaiadas. A maior variância encontrada refere-se à estaca de número 108, enquanto a menor refere-se à estaca de número 100.

A Figura 5 representa, graficamente, a variação dos valores obtidos para 0 índice esclerométrico de cada estaca. Por meio dela, é possível observar que há uma tendência para o valor do índice se encontrar próximo ao valor da resistência estabelecida no projeto $(20 \mathrm{MPa})$. Todavia, houveram valores externos a esta tendência, de modo que a única curva representativa de tendência para os valores do índice se comporta como um polinômio de grau 5. 
Figura 5 - Variação do índice esclerométrico para cada estaca.

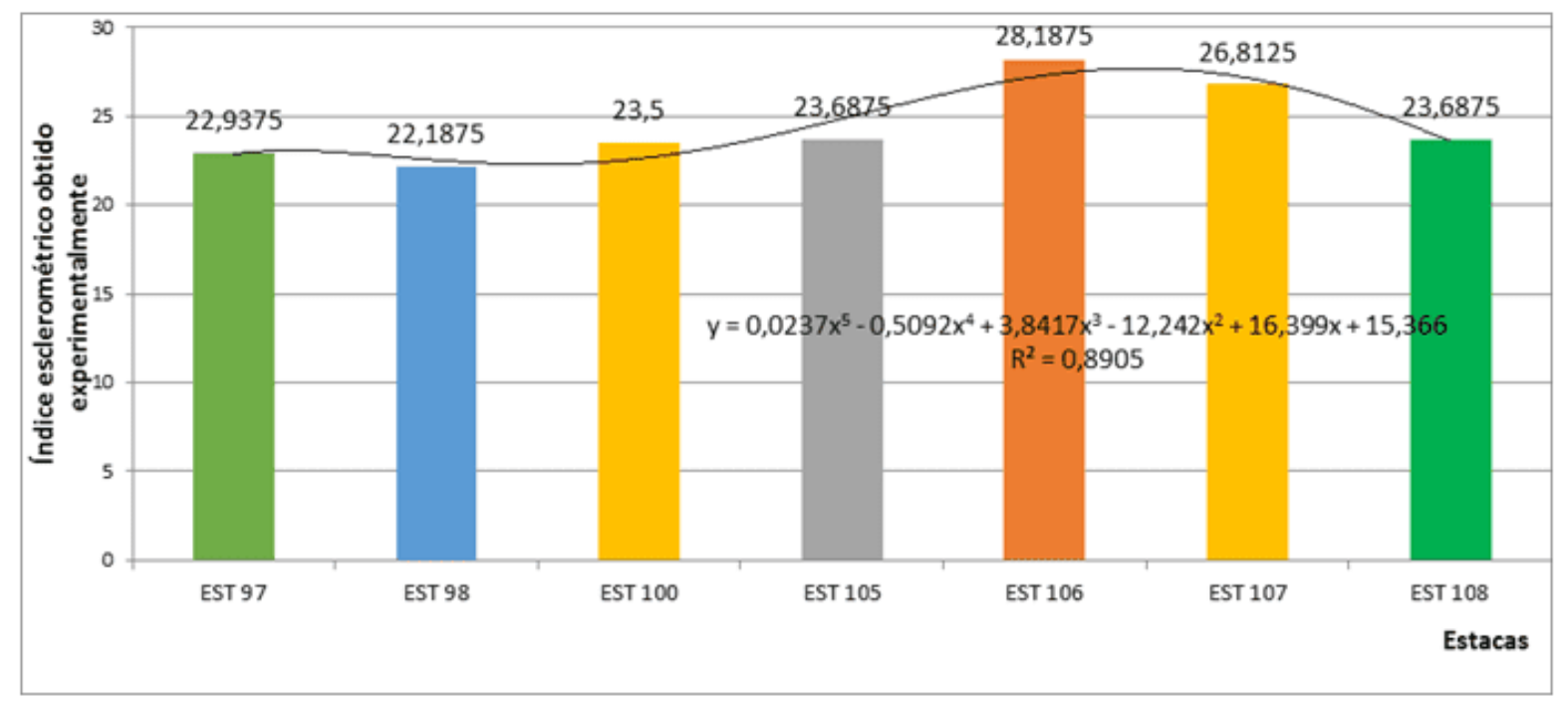

Fonte: Autores (2017).

\subsection{TESTE DE RESISTÊNCIA À COMPRESSÃO COM OS TESTEMUNHOS}

Os resultados obtidos para o índice esclerométrico de cada estaca se mostraram relativamente homogêneos. Todavia, ao se realizar a transformação de índice esclerométrico para um valor de resistência superficial, obteve-se um resultado inferior àquele estabelecido em projeto (20 MPa). Neste sentido, realizou-se uma contra prova ao ensaio de esclerometria: o ensaio de extração de testemunhos.

Por meio deste novo ensaio, foram extraídos dois testemunhos de concreto de cada estaca. Estas amostras foram levadas para laboratório a fim de serem ensaiadas à compressão axial simples e determinação de sua resistência superficial. A Tabela 2 apresenta os resultados desses ensaios.

Tabela 2 - Resultados do teste de resistência à compressão dos testemunhos extraídos das estacas.

\begin{tabular}{|l|l|l|l|l|l|l|l|}
\hline PROPRIEDADE & EST & EST & EST & EST & EST & EST & EST \\
& 97 & 98 & 100 & 105 & 106 & 107 & 108 \\
\hline
\end{tabular}




\begin{tabular}{|c|c|c|c|c|c|c|c|}
\hline Média (MPa) & 12,4 & 14,0 & 16,2 & 18,9 & 12,1 & 9,3 & 11,9 \\
\hline Desvio Padrão (MPa) & 0,3 & 1,2 & 0,1 & 2,0 & 2,8 & 0,2 & 0,47 \\
\hline $\begin{array}{l}\text { Coeficiente } \\
\text { Variação (\%) }\end{array}$ & 0,1 & 1,4 & 0,0 & 7,0 & 7,8 & 0,0 & 0,2 \\
\hline
\end{tabular}

Fonte: Autores (2017).

Não foi obtido o módulo de elasticidade dos testemunhos no ensaio de compressão axial.

Não foi realizados ensaios de carbonatação nos elementos analisados via esclerometria e talvez por isso, os valores de escleromeria tenha sido superiores aos valores de resistência à compressão via extração de testemunhos.

Neste sentido, a Figura 6 ilustra graficamente a variação da resistência superficial das estacas, obtida por meio do ensaio de extração de corpos de prova e compressão axial simples. Observa-se que os valores de resistência variaram bastante de uma estaca para a outra, caracterizando assim um universo de resultados bastante heterogêneo.

Figura 6 - Variação da resistência superficial das estacas medida pelo ensaio de extração e compressão.

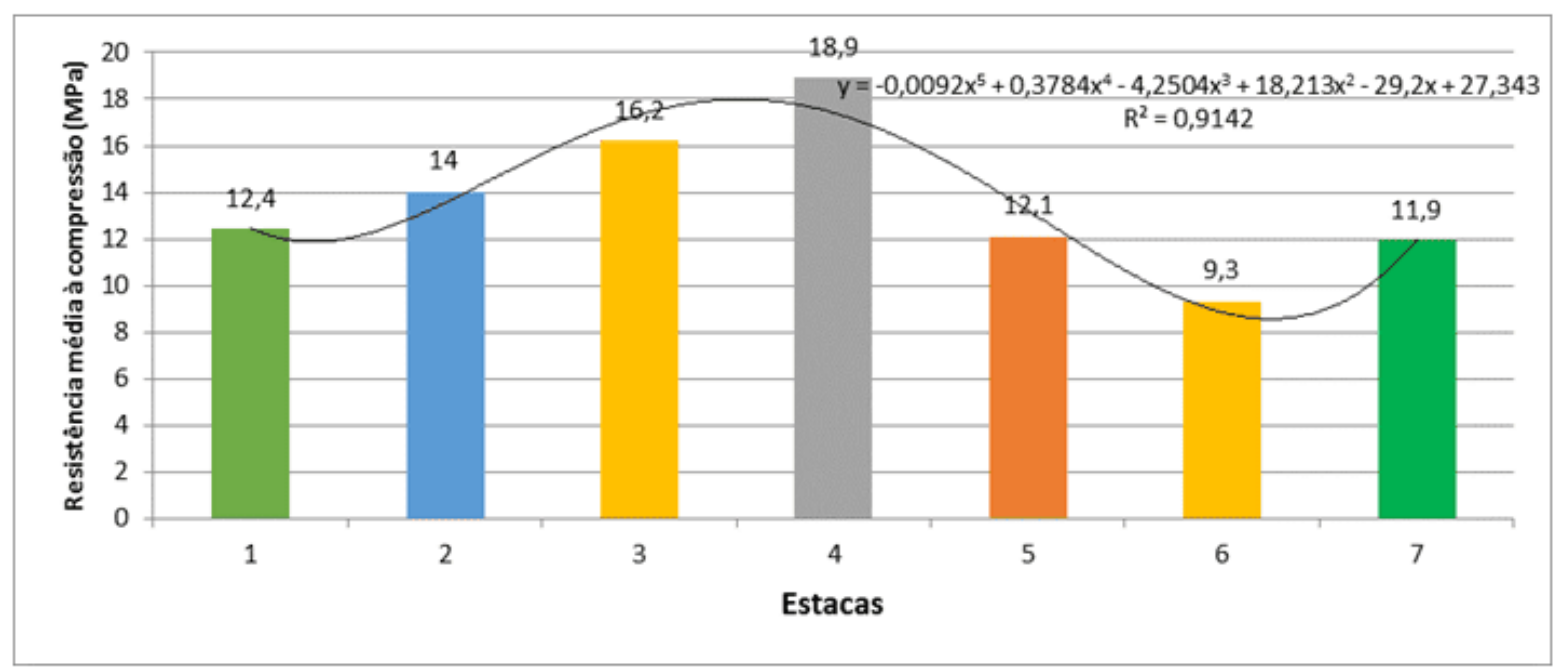

Fonte: Autores (2018). 
Além disso, não foi possível observar uma tendência de comportamento para os valores de resistência obtidos por meio do ensaio de extração e compressão axial simples. Desta forma, a linha de tendência que melhor se adequou aos resultados obtidos é caracterizada por um polinômio do quinto grau, tornando assim a análise de tendência viável apenas computacionalmente.

\subsection{COMPARAÇÃO DOS ENSAIOS: ESCLEROMETRIA VERSUS RESISTÊNCIA À COMPRESSÃO VIA EXTRAÇÃO DE TESTEMUNHOS}

Por fim, ao se analisar os valores conjuntos de resistência superficial das estacas do tipo hélice contínua, obtidos por meio das duas metodologias de ensaio (esclerometria e extração seguida por compressão axial), observa-se que os valores medidos por meio do ensaio de esclerometria se aproximaram mais do valor teórico estabelecido em projeto (20 MPa). A Tabela 3 ilustra estes valores, bem como o cálculo da resistência média de cada estaca, obtida por meio da média aritmética entre as resistências obtidas por cada procedimento de ensaio.

Tabela 3 - Resistência Superficial das estacas do tipo hélice contínua por diferentes modos de determinação.

\begin{tabular}{|l|l|l|l|}
\hline Estaca & $\begin{array}{l}\text { Resistência } \\
\text { (MPa) }\end{array}$ & $\begin{array}{l}\text { Esclerometria } \\
\text { (MPa) }\end{array}$ & $\begin{array}{l}\text { Projeto } \\
\text { (MPa) }\end{array}$ \\
\hline $\mathbf{9 7}$ & 22,9 & 12,4 & 20 \\
\hline $\mathbf{9 8}$ & 22,2 & 14,0 & \\
\hline $\mathbf{1 0 0}$ & 23,5 & 16,2 & \\
\hline $\mathbf{1 0 5}$ & 23,6 & 18,9 & \\
\hline $\mathbf{1 0 6}$ & $\mathbf{2 8 , 2}$ & 12,1 & \\
\hline $\mathbf{1 0 7}$ & 26,8 & 9,3 & \\
\hline $\mathbf{1 0 8}$ & 23,7 & 11,9 & \\
\hline
\end{tabular}

Fonte: Autores (2017). 
Com base nos dados representados na Tabela anterior, buscou-se representar graficamente as diferenças entre as resistências medidas por cada procedimento de ensaio. Deste modo, a Figura 7 ilustra esta variação na forma de um gráfico, salientando os variados valores de resistência obtidos.

Figura 7 - Variação da resistência à compressão por diferentes métodos de ensaio.

\section{Variação da resistência à compressão de estacas de fundação por diferentes métodos de ensaio}

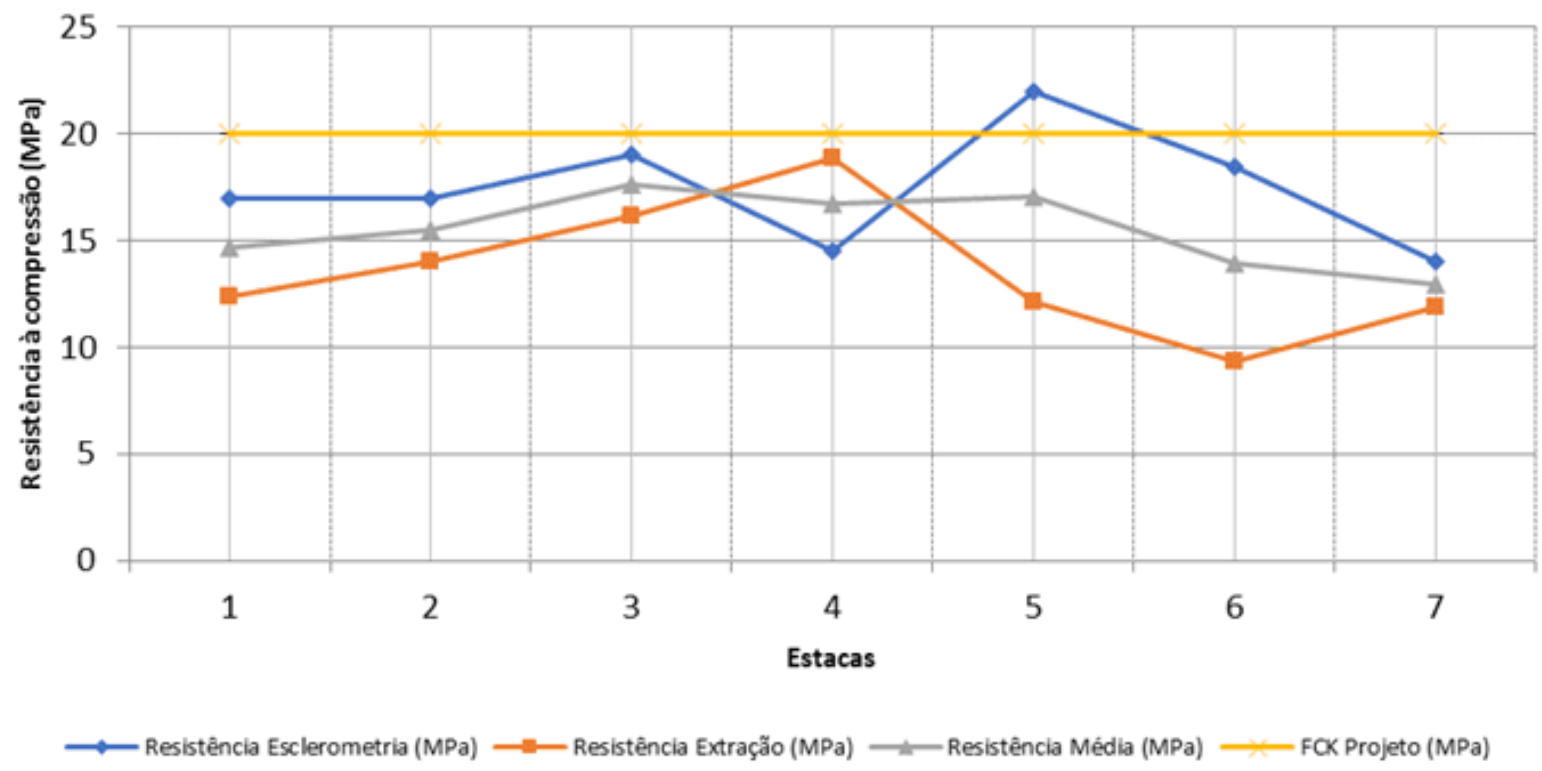

Fonte: Autores (2018).

Com base na Figura 7, é interessante analisar que os maiores erros foram alcançados nos valores de resistência obtida por meio do ensaio de extração de corpos de prova e compressão axial. Este fenômeno pode ter ocorrido devido a possíveis microfissuras e processos de fragilização dos corpos de prova durante os procedimentos de extração, contribuindo assim com a redução da resistência superficial dos mesmos. Todavia, todos os valores encontraram-se distantes da resistência superficial especificada em projeto, caracterizando assim a inconformidade da obra para com os padrões teóricos e os de projeto. 
Não ouve correlação linear entre os dados de resistência à compressão dos testemunhos extraídos e os de esclerometria $\left(R^{2}=0,24\right)$.

\subsection{ANÁLISE ESTATÍSTICA DOS RESULTADOS}

Conforme exposto anteriormente, este trabalho realizou a avaliação da resistência superficial de estacas de fundação do tipo hélice contínua, feitas em concreto armado, por meio da aplicação do ensaio de esclerometria de reflexão. Neste cenário, ao se analisar que os valores obtidos para resistência estavam distantes da resistência do projeto, optou-se por realizar uma contra-prova, por meio da aplicação do ensaio de extração de corpo de prova e compressão axial simples.

Todavia, observou-se que as duas metodologias de ensaio empregadas resultaram em valores diferentes para a resistência superficial das estacas. De modo geral, os valores de resistência via ensaio de esclerometria foram maiores que os valores de resistência via ensaio de extração e compressão axial. Deste modo, buscou-se realizar uma análise estatísticas da significância dos resultados encontrados, a fim de se determinar ou não uma relação entre os dois ensaios realizados.

A análise estatística realizada neste trabalho se baseou na promoção de uma ANOVA, ou seja, uma análise da variância. Esta ANOVA foi realizada por meio do software livre PAST, que também foi utilizado para se estudar a curtose e a obliquidade dos resultados. Os resultados para a ANOVAM encontram-se expostos na Tabela 4.

Tabela 4 - Análise de variância dos resultados obtidos.

\begin{tabular}{|c|c|c|c|c|c|c|c|}
\hline $\begin{array}{l}\text { Fonte } \\
\text { da } \\
\text { variaçã } \\
\text { o }\end{array}$ & $S Q$ & $\begin{array}{l}G \\
L\end{array}$ & $M Q$ & $\mathrm{~F}$ & $P$ & F crítico & Resultado \\
\hline $\begin{array}{l}\text { Entre } \\
\text { grupos }\end{array}$ & $\begin{array}{l}52,8457 \\
1\end{array}$ & 1 & $\begin{array}{l}52,8457 \\
1\end{array}$ & $\begin{array}{l}6,02393 \\
8\end{array}$ & $\begin{array}{l}0,0303 \\
5\end{array}$ & $\begin{array}{l}4,74722 \\
5\end{array}$ & $\begin{array}{l}\text { Significativ } \\
\text { O }\end{array}$ \\
\hline
\end{tabular}




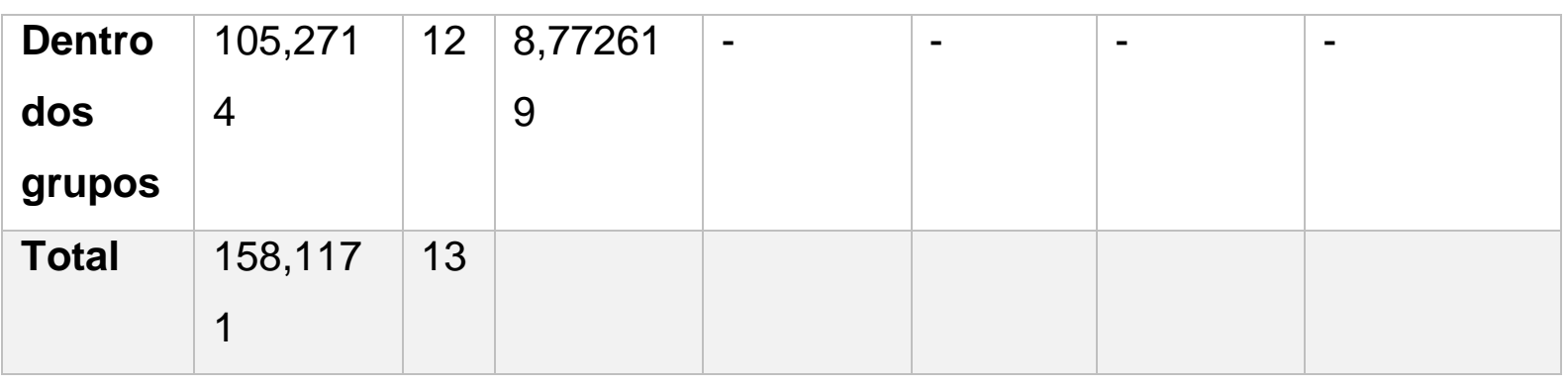

Fonte: Autores, 2018.

Em que:

$\mathrm{SQ}=$ Soma dos quadrados;

$\mathrm{GL}=$ Grau de liberdade;

$\mathrm{MQ}=$ Média dos quadrados;

F = Parâmetro de Fischer para significância dos resultados;

$\mathrm{P}=$ Coeficiente do Teste de Lavene;

F crítico = Parâmetro de Fischer crítico.

Com base na análise de variância explicitada na Tabela 4, observa-se então que os resultados obtidos para a resistência superficial das estacas, por meio dos dois métodos de ensaio, são significantes. Isto quer dizer que as duas metodologias experimentais para a avaliação de resistência possuem uma relação significante e apresentam dados homogêneos e confiáveis.

A homogeneidade e confiança destes dados pode ser afirmada tomando-se como base os resultados de curtose e obliquidade, conforme pode ser visto na Tabela 5, que apresenta um resumo estatístico dos dados de cada ensaio.

Tabela 5 - Resumo estatístico dos resultados obtidos.

\begin{tabular}{l|l|l}
\hline Informação & Esclerometria & Extração
\end{tabular}




\begin{tabular}{|l|l|l|}
\hline Número de observações & 7 & 7 \\
\hline Valor mínimo & 14 & 9,3 \\
\hline Valor máximo & 22 & 18,9 \\
\hline Somatória & 122 & 94,8 \\
\hline Média simples & 17,42857 & 13,54286 \\
\hline Erro padrão (\%) & 1,03756 & 1,195798 \\
\hline Variância (\%) & 7,535714 & 10,00952 \\
\hline Desvio padrão (\%) & 2,745126 & 3,163783 \\
\hline Mediana & 17 & 12,4 \\
\hline 1o quartil & 14,5 & 11,9 \\
\hline 3o quartil & 19 & 16,2 \\
\hline Coeficiente de variação (\%) & 15,75072 & 23,36127 \\
\hline Obliquidade ou assimetria & 0,3955309 & 0,6431692 \\
\hline Curtose & $-0,009528088$ & 0,2401887 \\
\hline
\end{tabular}

Fonte: Autores, 2017.

Os valores de curtose e obliquidade (ou assimetria) representados na Tabela 5 indicam, respectivamente, que os valores de resistência superficial das estacas obtidos pelas duas metodologias de ensaio possuem distribuição muito próxima de uma distribuição normal de probabilidade e não possuem valores extremos que impactem diretamente na homogeneidade dos valores.

\subsection{ANÁLISE GERAL DOS RESULTADOS OBTIDOS PELAS DUAS METODOLOGIAS DE ENSAIO}

Com base nos resultados obtidos, percebe-se que as estacas de fundação do tipo hélice contínua, em concreto armado, da obra do viaduto integrante do sistema BRT de Belém - PA, não atingiram a resistência superficial à compressão especificada em projeto, de valor igual a $20 \mathrm{MPa}$. Os valores experimentais obtidos variaram entre 12,95 MPa e 17,60 MPa. 
Estes valores de resistência podem ser indicativos da ocorrência de manifestações patológicas na estrutura de fundação analisada. Fenômenos como corrosão da armadura, percolação de íons cloreto na estrutura do concreto, instabilidade do solo local e atividades microbiológicas podem ocasionar a perda de resistência superficial de uma peça estrutural de fundação em concreto armado, por exemplo.

Além disso, problemas durante a fase de execução da obra, tais como insuficiência de vibração do concreto, falhas de concretagem, instabilidade das formas, entre outros, também podem ocasionar a redução de resistência superficial experimentada pelas estacas do tipo hélice contínua estudadas. Desta forma, torna-se necessário a realização de um estudo mais aprofundado com o objetivo de detalhar os mecanismos causadores do processo de perda de resistência diagnosticado por este trabalho.

\section{CONCLUSÕES}

Conforme exposto anteriormente, o objetivo fundamental deste trabalho foi avaliar a condição de dureza superficial de estacas de fundação do tipo hélice contínua por meio de uma metodologia não destrutiva à estrutura analisada. Neste sentido, concluiu-se que a aplicação do método de avaliação pelo ensaio de esclerometria de reflexão, normatizado pela ABNT NRB 7584: 2013 permitiu o desenvolvimento de um estudo de avaliação eficiente e preciso.

Dentro deste contexto, pôde-se concluir também que a esclerometria de reflexão é uma ótima metodologia de análise da resistência superficial de peças estruturas de concreto armado, visto que não provoca dados significativos à integridade e estabilidade total da peça ensaiada. Todavia, este procedimento não substitui os demais métodos de análise, de modo a ser necessário a elaboração de novos estudos com outras metodologias de ensaio a fim de otimizar a acurácia dos resultados de dureza superficial obtidos.

Para o caso das estacas de fundação da obra analisada, observou-se que apenas uma das estacas possuía resistência superficial maior do que mínima estabelecida 
em projeto. Deste modo, conclui-se que existe, no conjunto de estacas estudadas, algum tipo de anomalia que virá a prejudicar o desempenho estrutural das mesmas.

Portanto, sugere-se que sejam realizados outros estudos a fim de diagnosticar os fatores intervenientes e causadores da perda de dureza superficial das estacas de fundação analisadas. Com estes estudos, pode-se promover uma análise mais precisa e completa, de modo a auxiliar na mitigação de problemas com desempenho e durabilidade da edificação estudada no período pós obra.

\section{REFERÊNCIAS}

ANTUNES, W. R. TAROZZO, H. Estacas tipo hélice contínua. Editora PINI. São Paulo,1996.

ASSOCIAÇÃO BRASILEIRA DE NORMAS TÉCNICAS. NBR 7584: Avaliação da dureza superficial pelo esclerômetro de reflexão. Rio de Janeiro, 2013.

NBR 7680: Extração, preparo e ensaio de testemunhos de concreto. Rio de Janeiro, 2015.

. NBR 6118: Projeto de estruturas de concreto: procedimento. Rio de Janeiro, 2014.

CAPUTO, A. N. TAROZZO, H. ALONSO, U. R. ANTUNES, W. R. Estacas hélice contínua: projeto, execução e controle. Associação Brasileira de Mecânica dos Solos e Engenharia Geotécnica. São Paulo, 1997. 59p.

METHA, P. MONTEIRO, P. Patologia das construções. Editora IBRACON. São Paulo, 2014.

NEVILLE, A, M. Propriedades do concreto. Editora PINI. São Paulo, 1997.

PENNA, A. S. D. CAPUTO, A. N. MAIA, C. PALERMO, G. A estaca hélice contínua - experiência atual. Associação Brasileira de Mecânica dos Solos e Engenharia Geotécnica. São Paulo, 1999. 
4. Talvez pela ausência de controle de qualidade na produção do concreto no canteiro de obras.

Enviado: Maio, 2018.

Aprovado: Julho, 2019. 